\title{
POR QUE PRECISAMOS MULTIPLICAR INICIATIVAS DE VALORIZAÇÃO DO TRABALHO DOS PROFESSORXS? \\ RESENHA DE “... CURRÍCULOS EM REDES»i, ORGANIZADO POR CARLOS EDUARDO FERRAÇO, PARA OS LEITORES DA RIAE
}

Maria Luiza Süssekind ${ }^{\mathrm{ii}}$

Como resenhar um livro sobre os cotidianos de professorxs e estudantxs em salas de aulas de escolas públicas num momento tão triste para educação? A perda barulhenta e silenciosa de Regina Leite Garcia ressoa em minhasnossas palavras... Oportunamente, em entrevista ao Jornal A Página, em 2001 iii , ela já denunciava importantes ameaças para a construção da democracia e justiça social hoje em pleno curso, como o equívoco político e epistemológico da unificação curricular, os riscos da privatização da escola básica e o controle curricular exercido pelas avaliações externas. Também apontava que o maior problema para que a educação brasileira tivesse "qualidade" era "o salário" dos professorxs, "que é muito baixo." (GARCIA, 2001)

Com Regina, Nilda Alves e Ferraço, vimos aprendendoensinando a valorizar, ouvir e compartilhar as conversas com os tantos professores invisíveis que ousam trabalhar "inventando" (CERTEAU, 1994) soluções locais, fazendo com (idem) justiça e amorosidade (SKLIAR, 2008, p. 17), trabalhando no precário e perecível, mas com a potência que reside nas redes, nas trocas, na multiplicação da diversidade, na valorização da experiência e da copresença (SANTOS, 2004). As conversas, narrativas e relatos de professorxs sugerem a existência de outras possibilidades de fazer, aprender, pesquisar e a inexorabilidade do compartilhar... Sugerem que é isso que faz a riqueza do trabalho docente, a diversidade dos conhecimentos, a beleza dos cotidianos nas escolas, as políticas para diferença e as tessituras democráticas. Essa é nossa luta políticoepistemológica. O livro aqui resenhado é parte dessa luta. Enfrenta a proposta de valorizar os cotidianos escolares na forma, na concepção, nas escritas, nos temas...

Ao escrever a Apresentação de “... currículos em redes” com Carlos Eduardo Ferraço, chamamos atenção que o formato dos textos foi pensado e organizado sob a forma de platôs ${ }^{i v}$ de composição-produção de diferentes sentidos para os currículos realizados em redes nos cotidianos das escolas pesquisadas (FERRAÇO, SÜSSEKIND, 2016, p. 10). Trazendo resultados da pesquisa Currículos realizados nos cotidianos de escolas públicas do ensino 
fundamental: sobre narrativas e imagens produzidas com os usos, traduções e negociações como potência para a ampliação das redes de conhecimentos dos sujeitos praticantes, financiada pelo CNPq, que abrangeu 14 escolas da Rede Municipal de Ensino de Vitória, o livro evidencia a multiplicidade de usos (CERTEAU, 1994) que os professorxs, sujeitos praticantes dos cotidianos das escolas, fazem da proposta curricular prescritiva oficial. Assim, deslizando entre platôs, o leitor poderá lerverouvirsentir múltiplas e rizomáticas narrativasimagens dos currículos realizados nos cotidianos das escolas que potencializam práticas de inventividade e de resistência aos mecanismos homogeneizadores das prescrições curriculares oficiais (FERRAÇO, SÜSSEKIND, 2016, p. 10).

As narrativasimagens dos 17 capítulosplatôs encarnam diferentes processos curriculares realizados nos cotidianos daquelas escolas capturados em

\begin{abstract}
conversas, questionários, entrevistas, associação de palavras, depoimentos, observações, fotografias, filmagens, diários de campo, pautas, cadernos, bilhetes, grafites, murais, cartazes, publicações, materiais, jogos e livros didáticos, atividades escritas... Enfim, múltiplas possibilidades foram experimentadas nos cotidianos das escolas para a produção dos dados que pudessem ajudar a alcançar os objetivos pretendidos. (FERRAÇO, SÜSSEKIND, 2016, p. 10).
\end{abstract}

Enfrentando a linearidade, a explicabilidade e os constrangimentos propostos pelas palavras do reino da ciência, o livro “... currículos em redes” permite reconhecer que há vida nas escolas, que os conhecimentos e currículos e seus usos não são neutros e são desobedientes e que é importante negociar com as pessoas e com as palavras, seus sentidos e silêncios, seja nas aulas, nas pesquisas ou nas escritas.

Ainda, “... currículos em redes" é uma obra que valoriza o trabalho dos professorxs ao investir na contribuição que as narrativas das práticas pedagógicas podem oferecer para a tessitura de redes de subjetividades e conhecimentos (OLIVEIRA, 2007; SANTOS, 2004) entre os trabalhadores nas escolas, na formação de professorxs e interessados em educação em geral. Mas, também, valoriza os professorxs ao trazer resultados de pesquisa como prática de solidariedade, amorosidade e cumplicidade política. Nesse sentido, o livro potencializa o quase experimentalismo metodológico (MARCUS, 2014, SÜSSEKIND, 2012a ; 2012b) que os estudos com os cotidianos propõem. Em uma rede de colaboração, os professorxs, que são ali também pesquisadores, perseguiram tramas, pistas e alegorias (MARCUS, 1998) para "literaturizar a ciência", beber de todas as fontes (ALVES, 2001) como meio de enfrentar com astúcia (CERTEAU, 1994) as (im)possibilidades de "caçar a laço" o que se passa nos cotidianos 
- o que fazem os praticantes e como narram, o que narram sobre suas práticas e táticas gazeteiras - inventando metodologias, desinvisibilizando saberes (SANTOS, 2004) e bricolando (CERTEAU, 1994) conhecimentos e, assim, narram como foram astuciosamente criando, inventando, subvertendo e resistindo aos instituídos.

Ao usar (CERTEAU, 1994) narrativas e imagens, podemos trocar e compartilhar táticas e práticas, podemos reinventá-las. Reinventa-se, deste modo, o conhecimento e as práticas sociais, simultaneamente. Defend(em)o(s) com os estudos nosdoscom os cotidianos que as narrativas elaboram, ressignificam e talvez até conservem conhecimentos e práticas. Pensar com as redes e narrar suas histórias têm sido algumas das táticas usadas pelos praticantes do cotidiano (CERTEAU, 1994). Quando alguém nos faz um relato, ambos passamos por uma experiência única de conhecimento, pensamos e transformamos a nós mesmos e o mundo. (SÜSSEKIND, 2012). As narrativas de professorxs e estudantxs são a arte de pensarfazer com os currículos, de forma única e reflexiva. Como escreveu Pinar (2012): o professor é nesse sentido um artista, a conversa complicada é seu meio ${ }^{\mathrm{v}}$ de trabalhar e multiplicar modos de se fazer e existir no mundo (platô 4... e religiosidades, Adriana Pionttkovsky Barcellos e Danielle Piontkovsky, FERRAÇO, org, 2016, p. 61-78).

Os platôs do livro estimulam pensar a pluralidade de possibilidades de complexificação e de ampliação das redes de sentidos dos sujeitos praticantes em relação aos currículos realizados, caoticamente, potencializando nos cotidianos das escolas processos inventivos, anônimos e sorrateiros de táticas-estratégias de subversão das tentativas de padronização das noções de currículo presentes nos documentos das propostas curriculares prescritivas.

Perseguindo esta ideia, lembro que nos estudos com os cotidianos há argumentos que valorizam o trabalho docente como "uso" ou invenção, entendendo o papel criador dos "homens comuns" com Certeau (1994; SÜSSEKIND, 2012).

O autor não se refere a um uso qualquer que se faz a partir da apropriação de algo dado como tal. O uso a que Certeau se dedica é um uso particularizado a partir de táticas que podem burlar as estratégias impostas. Segundo esse autor, ao usar algo, as pessoas criam formas diferenciadas de viver o cotidiano. Tais práticas de uso, frutos da inventividade do mais fraco, não têm, necessariamente, que seguir o script traçado por quem produziu o que está sendo usado que, em geral, estrategicamente, tenta determinar a maneira como algo deve ser consumido. (...) Na contramão das perspectivas que veem o consumo como algo alienante, Certeau não acredita na dominação do homem, nem mesmo acha que o consumo é algo passivo. Para o autor, cada consumo corresponde a uma produção. (...) Portanto, para Certeau, para a produção visibilizada há outra produção invisibilizada a que ele chama de consumo. Dessa forma, o consumo não se trata de algo dócil, tampouco ligado à destruição, mas de algo ligado à criação, à produção. Produção de sentidos, 
de novas formas de uso, novas possibilidades de ser. Assim, o consumo/uso seria subversivo, visto que tece outras possibilidades para além daquelas esperadas. (platô 13... e consumos, Iorrana Fioreti de Menezes Pupa FERRAÇO, org, 2016, p. 1717-186).

Reconhecer professores e estudantxs por seu papel principal como fabricantes de conhecimentos (SÜSSEKIND, 2014a, p. 28) é uma das belas realizações desse livro que tenho o prazer de convidar, pela segunda vez, os leitores a percorrerem por suas próprias linhas de fuga.

Ajudando a defender que professorxs são tornados ruins quando exigimos que produzam resultados iguais (PINAR, 2012; SÜSSEKIND, 2014c), já que é impossível encontrar duas escolas iguais (EZPELETA; ROCKWELL, 1989, p. 58), o livro recém-lançado pelo charmoso professor da UFES, Carlos Eduardo Ferraço, e seu barulhento grupo de pesquisa encanta, teoriza, compartilha e enriquece nossos conhecimentos, mas também nosso compromisso com a escola pública e democrática. E, lembrando que é preciso

nos apropriar desse sorriso de menino para registrar os sentidos vividos pelos alunos das escolas públicas, os quais, de certa maneira, se reinventam em seus múltiplos espaçostempos e transformam, com a magia do viver, os seus próprios momentos singulares (platô 10... lazeres, Letícia Regina Souza Prezotti FERRAÇO, org, 2016, p. 139-150).

o grupo mostra, em mais uma obra, que o cotidiano se reinventa nas pesquisas, nas escolas, nas conversas de professorxs, nos currículos realizados, nas imagens, nas narrativas, nas escritas, nos amares, nos olhares, nos sentidos, desobedientemente, rizomaticamente, esteticamente, com as mãos dos artistas ordinários, solidários no fazer silencioso e contínuo do mundo em que vivemos. Porque, para nós, professorxs

coloca-se a necessidade de nos dedicarmos a problematizar a diferença que se manifesta no cotidiano escolar, não tendo como objetivo maior a busca pela norma e/ou pelo comportamento considerado padrão, até porque isso é sempre arbitrário, mas tendo como intenção ampliar as possibilidades de se viver a diferença na vida e, em particular, nos cotidianos das escolas. (platô 16 ... e sexualidades, Marco Antonio Oliva Gomes).

Enfim, em tempos de "Escola Sem Partido", vale terminar lembrando Paulo Freire, com Regina Leite Garcia, que nada do que se conta nesse livro seria possível se o trabalho docente não fosse entendido com um trabalho intelectual e criativo. Porque conhecimentos não são 
neutros. Porque os professorxs não pode[m] ser neutro[s], ele[s] [têm] de fazer parcerias (GARCIA, 2001).

\section{Boa leitura!}

\section{REFERÊNCIAS:}

ALVES, N. Decifrando o pergaminho: o cotidiano na escola nas lógicas das redes cotidiana. In: OLIVEIRA, I. B.; ALVES, N. Pesquisa no/do cotidiano das escolas, sobre redes de saberes. Rio de Janeiro: DP\&A, 2001.

CERTEAU, M. A invenção do cotidiano: 1. artes de fazer. Petrópolis, RJ: Vozes, 1994.

EZPELETA, J.; ROCWELL, E. Pesquisa participante. São Paulo: Cortez, 1989.

FERRAÇO; C. E.; SÜSSEKIND; M. L. Apresentação. In: FERRAÇO, C. E. (Org.). ...currículos em rede. Curitiba: CRV, 2016.

MARCUS, G. Ethnography through Thick \& Thin. New Jersey: Princeton University Press, 1998.

MARCUS, G. O intercâmbio entre arte e antropologia: como a pesquisa de campo em artes cênicas pode informar a reinvenção da pesquisa de campo em antropologia. Revista de Antropologia, v. 47, n.1, São Paulo, 2014.

OLIVEIRA, I. B. Aprendendo nos/dos/com os cotidianos a ver/ler/ouvir/sentir o mundo. Educ. Soc. [online]. v.28, n.98, pp. 47-72, 2007.

PINAR, W. What is Curriculum Theory. Second Edition, NY: Routledge, 2012.

SANTOS, B. S. (Org.) Conhecimento prudente para uma vida decente: um discurso sobre as ciências revisitado. São Paulo: Cortez, 2004.

SKLIAR, Carlos (Org.). Derrida \& a Educação. Belo Horizonte: Autêntica, 2008.

SÜSSEKIND, M.L. O ineditismo dos estudos nosdoscom os cotidianos: currículos e formação de professores, relatos e conversas em uma escola pública no Rio de Janeiro, Brasil. Revista e-Curriculum, São Paulo, v. 9, n. 2, p.1-21, ago. 2012. 
SÜSSEKIND, M. L. As artes de pesquisar nosdoscom os cotidianos. In: OLIVEIRA, I. B.;

GARCIA, A.. (Org.). Aventuras de conhecimento: utopias vivenciadas nas pesquisas em educação. 1ed.Rio de Janeiro: De Petrus/Faperj, v.1, 2014a. p.101-118.

SÜSSEKIND; M. L.. As (im)possibilidades de uma Base Comum Nacional. Revista E-cur-

riculum, São Paulo, v.12, n.03, p.1512-1529, out./dez.2014b. Disponível em: <http://revistas.pucsp.br/index.php/curriculum/article/view/21667/15917> Acesso em: 28 jul. 2016.

SÜSSEKIND; M. L. .. Quem é William F. Pinar? Petrópolis: DPetAlii, 2014c.

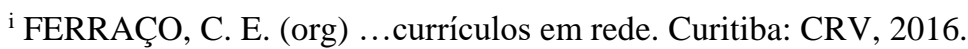

ii Maria Luiza Süssekind Verissimo Cinelli (Süssekind, M. L.) é licenciada em História pela Pontifícia Universidade Católica do Rio de Janeiro (PUC-Rio). Mestre em Ciências pelo Centro de Pesquisa em Ciências, Desenvolvimento, Agricultura e Sociedade da Universidade Federal Rural do Rio de Janeiro (CPDA/UFRRJ). Doutora em Educação pelo Programa de Pós-graduação em Educação da Universidade do Estado do Rio de Janeiro (ProPEd/UERJ). E pós-doutora pela The University of British Columbia/UBC, Canadá. Atua como professora adjunta II no Departamento de Didática e no Programa de Pós Graduação em Educação na Universidade Federal do Estado do Rio de Janeiro (PPGEdu/UniRio). Coordena o Projeto de Pesquisa e formação Pibid/Interdisciplinar. É líder do Grupo de Pesquisa Práticas Educativas e Formação de Professores (GPPF). É Coordenadora do GT de Currículos da Associação Nacional de Pós-graduação e Pesquisa em Educação (ANPEd). Tem como focos de pesquisa: epistemologias, currículos, formação de professores e estudos do cotidiano.

${ }^{\text {iii N }}{ }^{\circ} 103$ Ano 10, Junho 2001. http://www.apagina.pt/?aba=7\&cat $=103 \&$ doc $=8428 \& \mathrm{mid}=2$

iv A noção de platô usada no livro é inspirada em Deleuze e Guattari, referindo-se às regiões de intensidade contínua, que são constituídas de tal maneira que não se deixam interromper por uma terminação exterior.

v No original: "the teacher is in this sense an artist; complicated conversation is her or his medium".
} 